\title{
Generating Creativity in Elementary School Teaching: A Case Study of Teacher Professional Development in Indonesia
}

\author{
Yohana Triana Ina Weran, ${ }^{1 *}$ Paulus Kuswandono ${ }^{2}$ \\ 1,2 English Education Department, Sanata Dharma University, Yogyakarta, Indonesia
}

\begin{abstract}
Creativity plays an important role in education for both students and teachers. In this study, the researchers aim to investigate how teachers generate elementary students' creativity in the classroom. The study involved ten elementary school English teachers from ten schools in Sintang, West Kalimantan, Indonesia. This descriptive qualitative study employed snowball sampling by which the researchers invited one teacher to participate in this study and later the teacher suggested other potential participants that could be considered as the research samples. In gathering the data, the researchers identified teachers' perspectives in generating creativity using questionnaires and interviews. The questionnaires results were in the form of a Likert Scale and a diagram was employed to display the overall tendency. Further, interviews were descriptively analysed to support the results of the questionnaires. The results of this study demonstrated that in generating creativity in the classroom, the following criteria should be fulfilled: (1) students' mistakes should be welcomed and accepted as important part of learning; (2) students are expected to perform not only by constructing novel ideas, but also creating a product (outcome) that facilitates their creativity in the classroom. Other results close to the previous two main points are related to open-ended and real-life (authentic) tasks, resources availability, the atmosphere of care, and the teachers as a guide. In this study, the researchers provide data about how elementary school teachers generate creativity for elementary school students. It is suggested that further research should nurture and provide an atmosphere of care and physical environment to generate creativity.
\end{abstract}

Article Information

Received 01 February 2021

Accepted 04 July 2021

Published August 05, 2021

Keywords: brainstorming; creativity; meaningful feedback

\section{Introduction*}

Creativity has been the most frequently cited 'word' in $21^{\text {st }}$ century education because, in this 4.0 era, students are required to think, learn, and work critically. Creativity plays an essential part in students' development when they are required to design a concrete task or project. According to Falconer, Cropley, and Dollard

*Corresponding Author: Yohana Triana Ina Weran (yohana.weran@gmail.com) Jl. Affandi, Santren,
(2018), creativity is the heart of learning that includes idea generation, assumption making, problem-solving skills, and self-efficacy. Pang (2016) also points out that generating creativity is not easy especially in terms of problemsolving. It is because some students may not be accustomed to thinking creatively. Therefore, it is crucial to foster creativity starting from a 
young age as we can see the uniqueness of each student. However, in the case of elementary education, students need someone who can provide useful feedback to generate their creativity. Therefore, teachers are challenged asked to think resourcefully to foster students' creativity, such as to employ problem-solving skills, novel ideas, and new products. Moreover, generating creativity is aimed to increase knowledge of creative thinking and action in students (Beghetto, 2017). When teachers can think creatively, over time the students will adjust and try to get used to practicing the skill (Beghetto, 2017; Falconer et al., 2018; Kettler, Lamb, Willerson, \& Mullet, 2018; Pang, 2016).

Creativity is needed in the classroom to maintain activities in the classroom and also helps students to be more focused on carrying out the teaching and learning process. According to Schmoelz (2017), creativity is a circumstance that lives along with the individual that represents originality and value. For this reason, teachers are not only asked to stimulate students' creativity but also to show themselves as examples. Teachers cannot rely only on the fact that students can naturally become creative if they are provided with learning facilities. Rather, students can be creative if they are sparked by the teacher. Creativity does not come naturally as it takes effort to reach this skill level. Kettler et al. (2018) also argue that to produce creativity, teachers should focus not only on the preparation of the material but also on the way they approach their students. Thinking creatively means expressing a new idea that has never been raised. Lian, Kristiawan, and Fitriya (2018) indicate that Indonesia needs to focus more on developing creativity for students. Creativity in education is crucial that needs to be spot as a process that shows the wide affairs of life (Schmoelz, 2017).

According to Yasmin, Sohail, Sarkar, and Hafeez (2017), generating creativity can be developed along with the transformation of the concept of creativity, and it is regenerated to grow along with the times. The main purpose of generating creativity is to enable students to meet the challenges of their life and continue to learn (Tan, Lee, Ponnusamy, Koh, \& Tan, 2016). Tan et al. (2016) also explain that fostering creativity is seen as a social practice good both to students and the society level. Moreover, Brookhart and Mcmillan (2019) point out that brainstorming can be a creative activity for both teachers and students. Based on the interview, in elementary school, teachers can test the students to list several farm animals, imagine a hilarious or amusing moment that can happen on that farm and the students can pick one animal and write a story about it. This is an example of one of the activities created by the teacher to foster student creativity. A study by Brookhart and Mcmillan (2019) illustrates that teachers can engage students in class activities by brainstorming about what activities are interesting to do together in class. Several aspects need to be done by teachers and students in increasing creativity as follows: (1) recognizing the importance of deep knowledge, (2) being open to new ideas and actively seeking them out, (3) finding source materials in a wide variety of media, people and events, (4) organizing and reorganizing ideas, (4) using trial and error to see failure as an opportunity to learn.

Brainstorming and brainwriting can be done to generate creativity (Falconer et al., 2018; Vangundy, 2005). These two activities help to 
create new ideas based on some issues that happen in the society social environment and in a way that brainstorming focuses more on speaking, and brainwriting focuses more on writing. When teachers combine these activities, the balance of speaking and writing especially for students in the classroom can be examined. Vangundy also reminds teachers about the principles of creativity, namely separating idea generation from evaluation, testing assumptions, avoiding patterned thinking, creating new perspectives, minimizing negative thinking, and taking prudent risks (i.e., "you cannot be creative thinker unless you are a failure"). There are also top ten activities to help teachers and students think creatively. The main point of the activities are divided into three parts, which are (1) Combo Chatter which is to combine two related stimuli in a way to provoke ideas, (2) picture tickle refers to the use of unrelated pictures to generate ideas, and (3) what if...? which is the specific simple 'sentence trigger' to explore the limits of creativity.

The previous studies (Beghetto, 2017; Falconer et al., 2018; Kettler et al., 2018; Pang, 2016; Richardson \& Mishra, 2018) focus on teachers' and students' perspectives on how they use certain activities to generate creativity in the classroom. In those studies, students' creativity depends on the teachers' perceptions on how this skill can be honed in classroom practices. Grounded on this understanding, the students' creativity is often limited to the extent to which teachers view creativity. Departing from those studies, the researchers sought to investigate how elementary school teachers generate creativity in a classroom organized by the teachers. Generating creativity on the teachers' part is needed to help the students engage in classroom activity and get a good outcome for teachers or students. Teachers can also experience trial and error experiments to help them learn from the mistake to generate new ideas and ask other opinions to trigger their creative thinking. Ismail et al., (2020) also add that to ensure the delivery system become more effective and attractive, teachers need to stimulate students interest in learning by triggering their creative skills. Moreover, Huh and Lee (2020) explain that to generate the creativity teachers have to cooperate with the technology because creativity is the heart of all successful communication. Deriving from others' thinking, the teachers can take some points or ideas based on that so that they can produce their thinking related to classroom activities. The main reason why teachers should be creative is to make students engage with the class activity related to the subject of the activity, particularly English. Creativity helps teachers generate ideas while critical thinking skills enable them to evaluate and implement these ideas into practice. Deriving from the background of the study, the researcher posed the following question: "how do elementary school teachers generate creativity in the classroom?"

\section{Method}

This descriptive qualitative research aimed to investigate how elementary school teachers generate creativity in the classroom. The researchers involved chose ten English teachers from ten schools as the participants of this study. Initially, the researchers asked one participant to participate in this study then the participant suggested other participants who would be appropriate for the sample. Due to the COVID- 
19 pandemic, face-to-face interviews with the participants could not be conducted. Therefore, researcher distributed questionnaires in the form of a Likert scale using Google Forms which were subsequently followed up by a series of interviews. Questionnaires were essential in this study as they can provide the researchers with a general overview of their perceptions of creativity before interviews were conducted for more in-depth exploration. The interviews were carried out via WhatsApp (voice note and video call). The two options were provided to allow more options for this data gathering since the participants might have different preferences and agendas. Then, using snowball sampling, one of the teachers helped the researcher distribute the questionnaires to the other participants. Nine open-ended questions were used to identify how the teachers generate creativity in the classroom based on the study of Richardson and Mishra (2018). The data collected from the participants were then developed by the researcher by explaining them in paragraphs. The important points obtained are based on the study of Richardson and Mishra (2018). Before the elaboration process, the researcher looked at the results of the questionnaires in a form of diagrams and input them in the findings and discussion section. After that, the points from the diagram results were described in paragraphs.

\section{Findings and Discussion}

This study discusses how elementary school teachers in Sintang, West Kalimantan generate creativity from students in the classroom. The participants were 10 elementary school teachers in Sintang. To get the results of the study, the researchers used Google form with a Likert scale and ten open-ended questions. The theory is from Richardson and Mishra (2018). In their study, they identified nine aspects of the literature review in creativity. Those aspects are used by the researcher to identify the ways the teachers generated creativity this study of generating creativity in elementary school. The nine aspects from Richardson and Mishra (2018) include the followings: (1) tasks are openended/involve choice, (2) tasks are real-life, (3) students are enthusiastic/motivated, (4) mistakes are accepted, (5) new idea is encouraged, (6) resource availability, (7) physical environment, (8) atmosphere of care, and (9) teacher as a guide. From those aspects, the results are as follows: 


\section{Figure 1}

Nine Aspects of the Literature Review in Creativity

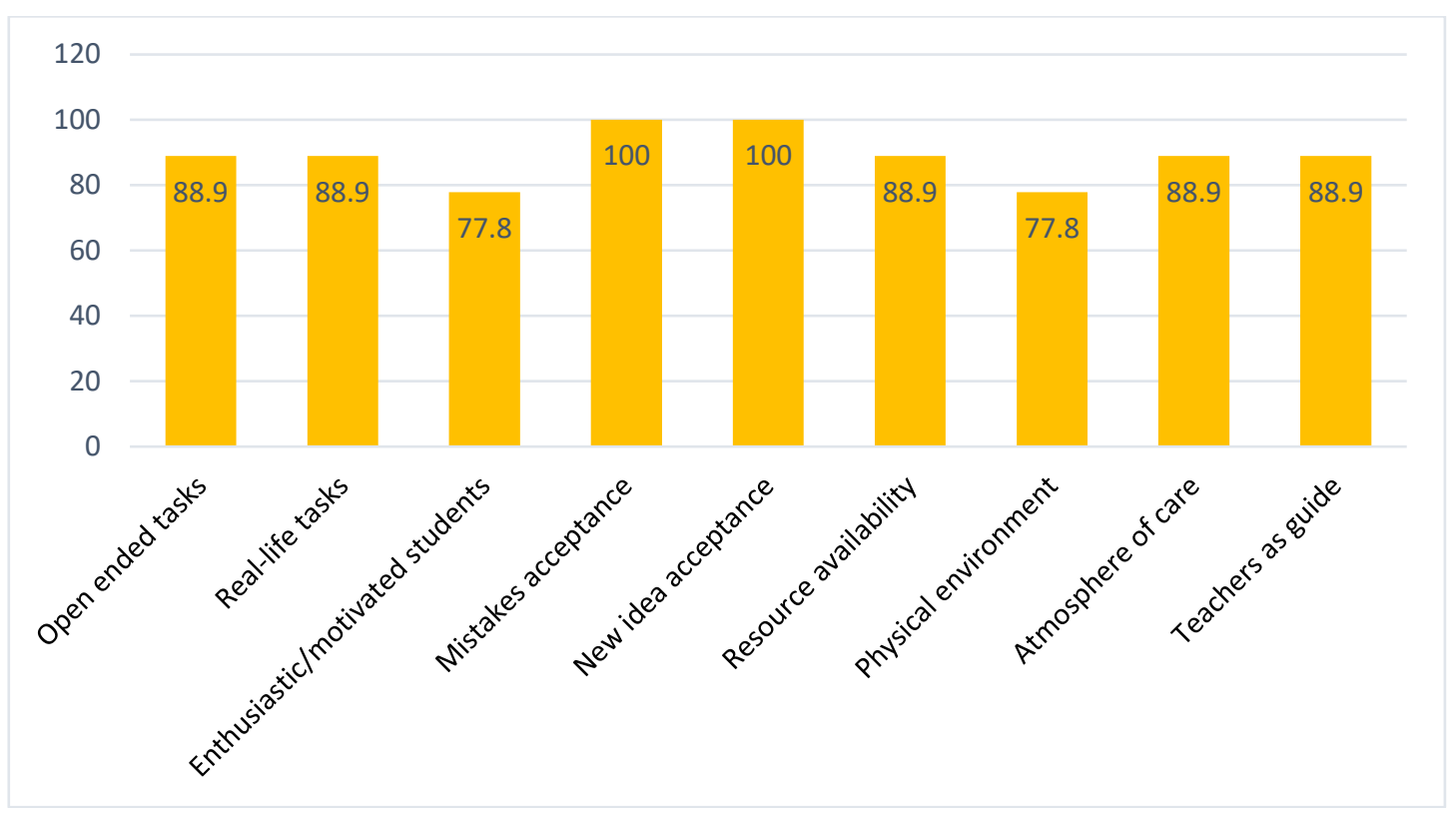

The results are aimed to answer the research question: how do elementary school teachers generate creativity in the classroom? From the results obtained, two components are fully agreed by the teachers, namely mistakes acceptance and new idea acceptance. The other variables that follow the previous two components are open-ended tasks, real-life tasks, resource availability, the atmosphere of care, teachers as a guide and two low points are enthusiastic/ motivated students and physical environment. The results are explained in the next section.

\section{Mistake acceptance}

Mistake acceptance is seen as a crucial component supporting creativity because it they identify that in the traditional class new idea is not well received. On the other hand, in this study teachers recognize that encouraging students to propose with the new ideas is a way to promote creativity. An environment that supports creativity is an environment that accepts mistakes and sees the mistakes as part of learning. In the interviews with the teachers, they described that when students made a mistake, the teachers did not directly give the punishment, but they gave the students motivation, meaningful feedback, and selfassessment. The self-assessment was done manifested by asking the students to write about what they have done. Giving feedback to the students is one of the best strategies in increasing students' performance (Brookhart \& Mcmillan, 2019).

Moreover, Brookhart and Mcmillan (2019) state that mistakes are the source of information both for teachers and students on misconception and gap. Furthermore, mistake acceptance refers to the tendency of using target language without being held back by worries about making mistakes (Alibeigynejad, 
2015; Brookhart \& Mcmillan, 2019). Based on the interview, the researcher found that mistake acceptance is an effective way in English learning because without making a mistake, the students cannot learn the target language effectively. The teachers must see the mistake as a natural part of the learning process to enable students' improvement especially in learning English. One of the teachers highlights that mistake acceptance is crucial because it enables students to learn from their mistakes and gain novel ideas or knowledge.

"When students make mistakes in the learning process, I try to provide a stimulus or bait questions so that the students can find the answers. It can make students remember the mistakes that have been made and they will not repeat the same mistakes"

Other teachers prefer to give feedback to the students without judging their answers or the teacher gives a big picture of why the answer is wrong. Furthermore, Schmoelz (2017) points out that creativity is a relation among individuals and communal efforts for acting and coping with ever-changing circumstances. With the everchanging circumstance, the individuals can learn how they face the circumstances based on the experience they have. Thus, if they make a mistake, they also know how to solve it.

\section{New idea acceptance}

The acceptance of new idea from the students is seen as the evidence of teachers who believe in the importance of creativity (Richardson \& Mishra, 2018). However, generating creativity through a new idea is not easy. In the classroom, teachers need to give time to the students to explore and broaden their understanding of making connections with a new idea. Higher-level questioning is one strategy that encourages deeper thinking and reflection and leads to the development of new ideas. In the interview, the teachers respond in various ways to trigger students' opinion, for instance, the teachers need to explore the students' abilities and then provide meaningful feedback by linking the learning topics to something that they like.

"Usually, I seek related topics based on the things or events that students like"

"For me, I look for topics that are appropriate to the students so that they are more interested in learning that topic"

"I favor preparing quizzes or guessing words"

Crossley, Muldner, and McNamara (2016) point out that a new idea is an important component of English learning, especially in writing. The study divided the human rating idea into four parts, which are idea fluency, idea flexibility, idea originality, and idea elaboration to see the quality of students' essays. Similar to this study, the teachers do not limit the students' ideas, even support any ideas that come from them. However, if the ideas do not have a relation to the material discussed, the teachers need to bring the students back into the material being taught. As Richardson and Mishra (2018) described in their study, a new idea cannot be separated from higher-level questioning, and this component is also part of high order thinking skills (HOTS). 
Furthermore, based on the study conducted by Indriyana and Kuswandono (2019), HOTS is important for students because if they have HOTS they can analyze, evaluate, and create their knowledge. With the importance of HOTS, the teachers should guide students to encourage them to think critically, for example by asking questions or imparting opinions. The teachers in this study also revealed that elementary school students sometimes have unique ideas that the teachers do not think of. This is crucial, considering that accepting new ideas is very much needed in the field of education and must be taught to young learners.

\section{Open-ended task}

Another method used by teachers in generating student creativity is open-ended tasks. According to Richardson and Mishra (2018), in this way, the teacher demonstrated the freedom of choice that leads to higher intrinsic motivation and support creativity. Open-ended tasks also help teachers engage students in rich discussions about the topic as well as ensure that students answer openly. Based on the interview, there are some ways to promote open-ended tasks to the students. For example, the exercises are given according to the topics discussed. If the students study about the classroom, then the teacher asks them to write what items are in the classroom. (2) The exercises are given in oral, written, practice, project, and product. Here the teacher asks students to make a product such as painting, writing, decorating based on the topic given. From these exercises, students observe their ability by creating something unique based on their preferences. (3) The assignments are given based on the exercise book. In the exercise book, students can explore the topic given by solving the assignments in the book. (4) The exercise is given after the teacher explains the outline of the topic discussed.

As explained by Richardson and Mishra (2018), 'open-ended tasks' are the way to represent the freedom of choice that leads to higher intrinsic motivation and creativity. In the case of building creativity, the teacher provides opportunities for students to choose by brainstorming. According to Brookhart and Mcmillan (2019), brainstorming is a creative activity especially for elementary school students (young learners). The activity can help students come up with broader ideas based on the topic presented by the teachers. For example, the teacher provides the keyword 'elephant' after that the teacher asks students to brainstorm about the word elephant and what can be made from this one word. From this activity, the teacher can see the creativity of the students who are given freedom in choosing certain keywords.

\section{Real-life task}

Real-life task is a component which is also interesting to the teachers. They said that if the exercise is associated with the surrounding events / real events, students can grasp the content of the lesson faster. Richardson and Mishra (2018) also highlight that 'real-life tasks' support students' creativity by providing opportunities to engage and to have a rich and meaningful learning experience. This also describes that students faster grasp the meaning of topics taught through friends or the surrounding community. Furthermore, teachers can provide experiences that make students more sensitive to environmental stimuli by providing tasks that are related to real events (Falconer et al., 2018). In the interview, there 
were several points raised by the teachers regarding this aspect. The teacher must know in advance the events being talked about by students and then use that as a direction in giving assignments. The teacher asks students to relate experiences they have seen/experienced by giving directions in English, and the teacher gives direct instruction by pointing names of objects in the class using English.

According to Pang (2016), creativity is generally conceptualized as the ability to produce something new and useful. For something to be useful, the teachers need to give an assignment based on surroundings or recent phenomena. By giving assignments that are related to real-life, students do not only develop from a book perspective but also from a practical perspective. Therefore, Richardson and Mishra (2018) emphasize the utilization of assignments based on real-life tasks that are useful for students. According to Kettler, Lamb, Willerson, and Mullet (2018), 'real-life tasks' support personal endeavors and social fulfillment to achieve self-fulfillment. If this can be taught from an early age through 'real-life tasks' given by the teacher, the students will know and master the skill well.

\section{Resource availability}

Resource availability is the key element in generating students' creativity. Richardson and Mishra (2018) mention that resources provided by teachers serve as the infrastructure of creativity, including digital or non-digital resources. They can encourage the articulation of creative expression. In the interview, the teachers pointed out that generating students' creativity can be done by providing resources as follows (1) providing learning media and fun methods for students, (2) providing indoor and outdoor activities that can boost students' speaking skills such as games, direct conversations, or giving questions of the day ("what is your favorite color?" "why you choose that color?") and giving videos in English. Moreover, the teacher can ask students to sing and play so that they will not be bored.

In encouraging creativity of the students, teachers have to provide some activities that allow students to enjoy the learning process such as drawing, singing, and painting. These activities need to be done by the teachers in the class. The activities also help teachers in generating students' creativity with various abilities that they develop in the classroom. Yasmin et al., (2017) point out that teacher is the center of promoting self-determination in a classroom, and to engage with students. Teachers also need to focus on resource availability. Students can enhance their creativity by using some methods including media to learn. Creativity can be carried out not only by teachers and students but also from the complete equipment or resources to support students' abilities in academic and nonacademic matters (Yasmin \& Sohail, 2018; Yasmin et al., 2017). Moreover, teachers have to encourage students' creativity by accommodating or providing places in which learning can be joyful. With the existence of adequate and complete resources, students can express their learning process in a variety of ways. The students can reap the opportunity to apply new knowledge and see its value beyond the boundaries of the school (Kettler et al., 2018). The existence of adequate resources can also help students when they make a product. The supporting facilities provided by the school is also very important for the development of 
students' creativity in school and also to convey their learning.

\section{Caring Atmosphere}

Caring atmosphere is important for both students and teachers. Teachers must be able to develop a good relationship by accepting whoever the students are and recognize their interests. By accepting the students' interests, the teachers can fully understand the abilities of each student in a classroom and make learning and teaching approaches more effective. It also helps teachers recognize the potential of each student and try to encourage these abilities to increase their performance in the class. According to Soh (2017), students' creativity can be heightened through social modeling, reinforcement, and classroom ecology. The behavior of the teachers plays a critical role in a classroom. Therefore, it is necessary for the teachers to foster students' social activities in a classroom. Building positive creativity is the ability to express feelings since they are ways to develop students' learning. In the interview, one of the teachers focuses on the activity in the classroom that can support the action of caring or respect with other opinions.

"I prepare a cooperative learning method so that students learn to respect the ideas or opinions of their classmates. For example, I decided to form a small group. Each group has different topics, then I ask them to discuss it, later I ask them to present the topics"

That activity aims to construct a caring atmosphere an atmosphere of care by teaching them to respect other opinions and learn to listen. Other activities that can be carried out by the teachers in supporting this aspect include doing cooperative learning that enables students to work together and build a relationship to respect each other opinions, giving compliments if students can answer the question given by the teacher correctly, and giving time for students to express or respond to each other's opinions.

According to Hartzell and Greene (2017), in the creativity-fostering classroom, teachers generate and maintain the climate in which students are respected. They are asked to tolerate and accept a new ideas. The diversity in giving an opinion must be encouraged and appreciated by the teachers and also the students. An attitude of mutual respect between students in the classroom will make the classroom atmosphere better and more enthusiastic because the students can openly express their opinions. It would be better if this activity is carried out since elementary school. With the increasing diversity of opinions and ideas in the classroom, teachers can take advantage of the positive aspects of this diversity and make efforts to encourage creative problem solving and the formation of new ideas among students. Discussing creativity and its relationship with students' concerns opens up a new definition that creativity is not only related to cognitive aspects but also affective ones. Teachers are expected to teach, nurture, and evaluate students' creativity (Patston, T. P., Cropley, D. H., Marrone, R. L., \& Kaufman, 2017). Their research demonstrates that creativity constitutes human's ultimate resource and creativity is related to intelligence and personality. 


\section{Teacher as a guide}

Teachers play an important role as a guide by the teachers who continuously question, learn, and experiment alongside their students (Richardson \& Mishra, 2018). 'Teachers as a guide' is essential because in the classroom they play an important role by evaluating students' performance, providing meaningful feedback, and also evaluating students' strengths and weaknesses (Brookhart \& Mcmillan, 2019). Teachers are also expected to realize that they are significant gatekeepers in the development of students' creativity. Teachers do not only teach, but also help and give encouragement to the students. In the interview, the teachers highlighted some points that are related to this aspect (1) providing an effective learning method to the students to explore their knowledge, (2) giving students time to read the book, and then asking their opinion about the topic in the book, and (3) showing trust to the students without under pressure their ability and their thinking. The teachers also responded by giving their several thoughts related to the teacher as a guide as follows:

"Before going into the main topic of the lesson, I give the students time to read the material first then appoint several students to convey what they understand after reading the material and I will conclude together with them"

"I put my trust in students without having to pressure them so they will naturally get used to it"

"Commonly, I form groups randomly and giving a kind of bait question to create curiosity among students and digging for information among them"

The researchers found that the teachers are very supportive of students' creativity in various ways, for example by giving prompt questions, building a classroom atmosphere through games, and also asking for ideas when giving a variety of topics. However, this is contrary to Hartzell and Greene's (2017) opinion which underlines that elementary school teachers do not implement strategies that foster creativity in students. On the contrary, in this study, the researcher verified that the teachers can help students by providing various ways to improve their creativity skills. The students' creativity will not develop well without teachers' guidance. Therefore, the teacher as a guide is very important in developing creativity. Likewise, Pang (2016) highlights that creativity can be described as a type of idea generation if it is put under a learning context and it focuses on results. To keep the learning context on track, it is the teachers' responsibility to keep students on the right track according to the topic or context that has been set.

\section{Motivated students}

The next component is motivated students. This aspect gets low points from the teachers because the lesson is in English, and the language is rarely used by elementary school students in their daily life. One of the teachers stated that students will be very passionate about learning if the teacher also provides games in English, and also prepare the physical activity. According to Richardson and Mishra (2018), students' contributions to the class must be valued and trusted by the teacher so that they will have enthusiasm in adhering to the 
learning process. The researcher points out some statements from the teachers as follows (1) using student-centered approach, (2) developing a good approach to students such as creating stories in English, games, and also singing together especially for classes 2 and $3,(3)$ giving prompt questions for students to express their opinions, and (4) giving compliments and encouragement to students if they can express their opinions and answering questions.

Hartzell and Greene (2017) point out that the motivation given by the teachers can be applied in various situations. With the flexible strategies, students can transfer their learning to different situations and this is very useful for them in real life. Even though the result of the data collection shows that 'enthusiastic/motivated students' get a low response, the teachers explained that with various ways of teaching, the students' motivation for taking English subjects will increase.

\section{Physical environment}

Another component that gets low points from the teachers is the physical environment. Based on the study from Richardson and Mishra (2018), the physical environment plays an important role because it provides places for collaborative work that support students' creativity. Although this point did not get as many points as other aspects, it does not mean that this aspect is not useful in developing students' creativity. One teacher stated that although this activity was rarely used at school, it did not mean this activity was never carried out by the teacher. The teacher said that the students are very happy when it comes to the physical environment such as mentioning the names of flowers in the schoolyard using English or the teacher makes a game that involves physical activities such as pointing body parts in English. For classes 2 and 3, they enjoy this activity because the teacher also provides traditional games in this activity. For example 'tabak' is to encourage students to be cooperative because it requires teamwork and tactics. Next, the activity using 'sumpit' (blowpipe made of bamboo) enables students to be more careful and accurate in what they do. In addition, 'telok penyok' game that depicts a mother of turtle trying to keep her eggs from being stolen could be an effective resource to enhance the students' creativity. In this game, the teacher tries to give instructions using English to make students get used to English.

\section{Conclusion}

The study involving English teachers in Sintang, West Kalimantan, demonstrates that there are two important points in generating creativity in the classroom, which are accepting mistakes and accepting new ideas given by the students. 'Accepting mistakes' from students and considering the mistakes as lessons for students is the way to promote creativity. They also add that an environment that supports creativity is an environment that accepts a mistake and sees that as part of learning. 'new idea acceptance' is also an important component in generating student creativity because this means the teachers trust their students and can encourage students to explore, broaden understanding, and make connections. Moreover, open-ended tasks mean the teacher demonstrated the freedom of choice that leads to higher intrinsic motivation and support creativity. The open-ended tasks also help teachers engage students in rich discussions 
about the topic as well as to ensure that students answer openly.

The component of 'real-life tasks' is also crucial as the exercise is associated with surrounding events or real events that can facilitate the students to grasp the meaning of the lesson quickly. Furthermore, resource availability means that the resources provided by the teacher serve as the infrastructure of creativity such as digital or non-digital media that encourage the articulation of creative expression. The other significant component is the caring atmosphere. Teachers must be able to form a good relationship by accepting students for whoever they are and recognizing individual interests. By accepting the students' interests, the teacher can fully understand the abilities of each student in a classroom and make learning and teaching approaches more effective. Teacher as a guide means that teachers have a critical role. They continuously question, learn, and experiment with their students.

The motivated students got low points from the teachers because the lesson is in English, and students rarely used the language in their daily life. In solving the difficulty, one of the teachers created some games in English with some physical activities. The last is the physical environment. This aspect plays an important role because it provides places of collaborative work that support students' creativity. Although this point did acquire relatively high points in comparison to the other aspects, it does not mean that this aspect is not useful in developing student creativity.

For the future research direction, the researchers point out that the caring atmosphere is worth discussing. This study has discussed that the social relationship among students in the classroom can foster creativity. Nevertheless, this study only focuses on the meaning of the atmosphere of care within the context of the teacher-student relationship. Thus, future researchers can discuss the extent to which the relationship among students in the classroom can help them develop their creativity. The physical environment can also be discussed in the future considering that the current situation requires students to take part in online classes. A research question that might be asked can center around the context of how teachers maintain students' creativity skills through the physical environment during or post-pandemic situations.

\section{References}

Alibeigynejad, M. (2015). The effect of Iranian university teaching EFL students ' beliefs on English language learning. International Conference on Research in Science and Technology.

Beghetto, R. A. (2017). Creativity in teaching. The Cambridge Handbook of Creativity across Domains, 549-564. https://doi.org/10.1017/978131627438 5.030

Brookhart, S. M., \& Mcmillan, J. H. (2019). Classroom assessment and educational measurement. https://doi.org/10.4324/978042950753 3

Crossley, S. A., Muldner, K., \& McNamara, D. S. (2016). Idea generation in student writing: Computational assessments and links to successful writing. Written Communication, 33(3), 328-354. https://doi.org/10.1177/074108831665 0178

Falconer, E. G., Cropley, D. H., \& Dollard, M. F. (2018). An exploration of creativity in 
primary school children. International Journal of Creativity and Problem Solving, 28(2), 7-25.

Hartzell, S. A., \& Greene, M. T. (2017). Fostering creativity in the classroom : Effects of teachers' epistemological beliefs, motivation, and goal orientation. (September 2009). https://doi.org/10.1002/j.21626057.2009.tb01314.x

Huh, K., \& Lee, J. (2020). Fostering creativity and language skills of foreign language learners through SMART learning environments: Evidence from fifthgrade Korean EFL learners. TESOL Journal, 11(2). https://doi.org/10.1002/tesj.489

Indriyana, B. S., \& Kuswandono, P. (2019). Developing students' higher order thinking skills (HOTS) in reading: English teachers' strategies in selected Junior High Schools. JET (Journal of English Teaching), 5(3), 204. https://doi.org/10.33541/jet.v5i3.1313

Ismail, S. N., Abdullah, Z., Komariah, A., Kurniatun, T. C., Kurniady, D. A., Sunaengsih, C., \& Sanjaya, A. J. (2020). Influence of the professional learning community of malay language teachers at the transformation school in Selangor. International Journal of Innovation, Creativity and Change, 12(6), 236-254.

Kettler, T., Lamb, K. N., Willerson, A., \& Mullet, D. R. (2018). Teachers' perceptions of creativity in the classroom. Creativity Research Journal, 30(2), 164-171.

https://doi.org/10.1080/10400419.2018 .1446503

Lian, B., Kristiawan, M., \& Fitriya, R. (2018). Giving creativity room to students through the friendly school's program. International Journal of Scientific and Technology Research, 7(7), 1-7. https://doi.org/10.31219/osf.io/zebpd
Pang, W. (2016). Promoting creativity in the classroom: A generative view.

Psychology of Aesthetics, Creativity, and the Arts, 9(2), 122-127.

https://doi.org/10.1037/aca0000009

Patston, T. P., Cropley, D. H., Marrone, R. L., \& Kaufman, J. C. (2017). Teacher selfconcepts of creativity: Meeting the challenges of the 21 st century classroom. International Journal of Creativity and Problem Solving, 27(2), 23-34. Retrieved from https://www.researchgate.net/publicati on/321024739

Richardson, C., \& Mishra, P. (2018). Learning environments that support student creativity: Developing the SCALE. Thinking Skills and Creativity, 27, 45-54. https://doi.org/10.1016/j.tsc.2017.11.0 04

Schmoelz, A. (2017). On co-creativity in playful classroom activities. Creativity. Theories - Research - Applications, 4(1), 25-64. https://doi.org/10.1515/ctra2017-0002

Soh, K. (2017). Fostering student creativity through teacher behaviors. Thinking Skills and Creativity, 23, 58-66. https://doi.org/10.1016/j.tsc.2016.11.0 02

Tan, L. S., Lee, S. S., Ponnusamy, L. D., Koh, E. R., \& Tan, K. C. K. (2016). Fostering creativity in the classroom for high ability students: Context does matter. Education Sciences, 6(4). https://doi.org/10.3390/educsci604003 6

Vangundy, A. B. (2005). 101 Activities for Teaching Creativity. San Francisco: John Wiley \& Sons, Inc.

Yasmin, M., \& Sohail, A. (2018). A creative alliance between learner autonomy and English language learning: Pakistani university teachers' beliefs. Creativity Studies, 11(1), 1-9. https://doi.org/10.3846/23450479.2017 
Yohana Triana Ina Weran, Paulus Kuswandono

.1406874

Yasmin, M., Sohail, A., Sarkar, M., \& Hafeez, R. (2017). Creative methods in transforming education using human resources. Creativity Studies, 10(2),

145-158.

https://doi.org/10.3846/23450479.2017 .1365778 